\title{
Implant failure: Etiology and complications
}

\author{
Salah Sakka ${ }^{1}$, Paul Coulthard ${ }^{2}$
}

\author{
${ }^{1}$ DDS MSc PhD. Senior Clinical Lecturer in Oral and Maxillofacial Surgery, Faculty of Dentistry, The University of Albath, \\ Homs, Syria \\ ${ }^{2}$ BDS MDS PhD. Professor in Oral and Maxillofacial Surgery, School of Dentistry, The University of Manchester, Manchester, \\ United Kingdom
}

Correspondence:

Abdul Hameed Droubi St

Plaza Building, Floor 2

PO Box 2137 Homs, Syria

salah.sakka@hotmail.com

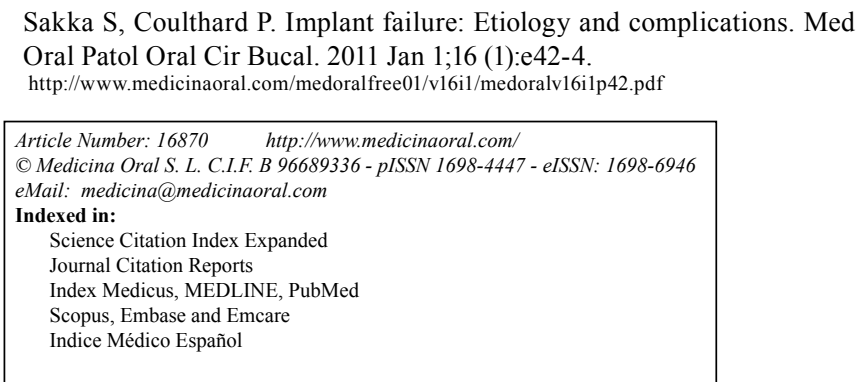

\begin{abstract}
The possible occurrence of implant failure is a major concern for implantologists and knowledge in such unavoidable fact is clinically essential. Periimplantitis is an inflammatory response in which there is a loss of the bony support of the implant. Diagnosis is based on the clinical signs of infection such as hyperplastic soft tissues, suppuration, colour changes of the marginal peri-implant tissues and gradual bone loss. This site-specific infection may have many features in common with chronic adult periodontitis. Surgical trauma, micromotion and overload are also considered to be associated with implant failures. The lack of osseointegration is generally distinguished by implant mobility and radiological radiolucency. Here, the implant is considered to be failed . Progressive marginal bone loss without marked mobility is referring to a failing implant. The purpose of this concise review was to discuss the implant complications and failure by highlighting the major etiologic factors as well as the parameters used for evaluating such failure.
\end{abstract}

Key words: Implant failure, peri-implantitis, marginal bone loss, implant mobility.

\section{Introduction}

Implantology is continually developing as new research results provide a better understanding of the biologic principles that direct the development of a dynamic interface between the living tissue and an artificial structure. However, in spite of high success rate, occurrence of implants failure has been reported (1).

Implant failure may be referred to as the status of the implant performance that when using some quantitative measurements, falls below an acceptable level. This definition encompasses clinical situations, ranging from all symptomatic mobile implants to implants show more than $0.2 \mathrm{~mm}$ of peri-implant bone loss after the first year of loading (2) or bleeding depth exceeding $5 \mathrm{~mm}$ of probing depth (3). The distinction between failed implant and failing implant is clinically important. The lack of osseointegration is generally characterized by implant mobility and peri- fixtural radiolucency. In this situation, the implant is considered to be "failed" (4). On the other hand, the failure process might be slow and continuing (5). Therefore, an implant characterized by progressive marginal bone loss without marked mobility is considered to be "failing" (4). 


\section{Implant complications and failure}

A multifactorial background for implant complications and failure has been extensively reviewed (6). Three major etiologic factors have been suggested:

1- Infection: Bacterial infection that leads to implant failures can occur at any time during implant treatment (7). Several terms are currently used indicating failing implants or complications. These are: peri-implant disease, peri- implant mucositis, and peri-implantitis. Peri-implant disease is a collective term for inflammatory reactions in the soft tissues surrounding implants. Peri-implant mucositis is a term describing reversible inflammatory reactions in the soft tissue surrounding implants. Other soft tissue complications (hyperplastic mucositis, fistulations and mucosal abscess) seem mainly to have an infectious etiology (8). Fistulations and hyperplastic mucositis are often found in relation to loose prosthetic components (9). Abscesses can occasionally be seen in relation to food particles trapped in the periimplant crevice (10). Peri-implantitis is referred to as inflammatory reaction with loss of supporting bone in the soft tissues surrounding implants $(8,11)$. Plaqueinduced infection as a result of plaque accumulating on the exposed surfaces of the biomaterial (12) could be included in the definition of peri-implantitis. The latter authors regarded peri-implantitis as site-specific infection having many features in common with chronic adult periodontitis.

2- Impaired Healing: It is believed that the magnitude of the surgical trauma (lack of irrigation and overheating), micromotion and some local and systemic characteristics of the host play a major role in implant failures related to impaired healing (10).

3- Overload: Implant failures related to overload include those situations in which the functional load applied to the implants exceeds the capacity of the bone to withstand it. Failures that happen between abutment connection and delivery of the prosthesis, probably caused by unfavourable loading conditions or induced by the prosthetic procedure, considered to have an overload etiology (5). Other attributes to implant failures are poor surgical technique, poor bone quality and poor prosthesis design in addition to the traumatic loading conditions (13).

\section{Parameters used for evaluating implant failure}

Several variations in the evaluation methodology have to be in mind, since implants are branded by different designs and subjected to different surgical techniques and loading conditions. The most common diagnostic criteria used for the assessment of implant failures are:

\section{1- Clinical signs of infection}

Infection is the most common explanation for complications that might occur during the healing period. These complications may include swelling, fistulas, suppura- tion and early/late mucosal dehiscence can occur and may point to implant failure. Nevertheless, early wound dehiscence can also be present in relation to retained sutures, inadequate flap designs, or premature wearing of a denture (14).

Early signs may be a mark of a much more critical result than if the same complications occur later, because of disturbance of the bone healing process that leads to the integration of the implant. Late signs of progressive marginal infection can lead to implant failure (15). However, clinical signs of infection such as hyperplastic soft tissues, suppuration, colour changes of the marginal peri-implant tissues, etc., are signs, which need an intervention. Therefore, signs of infection either early or late can not be used alone to determine the fate of an implant, but should be evaluated in relation to other parameters such as radiographic changes and mobility. In the absence of the latter parameters, clinical signs of infection that if left untreated, might lead to an implant failure. In other words, signs of infection point to more a complication than a failure.

\section{2- Clinically marked mobility}

Mobility of implants is the key sign of their failure. This clinically noticeable situation can, occasionally, be present without distinct radiographic signs of bone changes (16). Several different kinds of mobility: horizontal, vertical and rotation mobility have been recognized (17). The reverse-torque test was proposed to discover mobile implants (18) and the periotest device can be used for a better evaluation of horizontal mobility (19).

While rotational mobility may reflect an immature bone/implant interface, horizontal and vertical mobility on the other hand, may be associated with bone loss and the presence of soft tissue capsule (8).

\section{3- Radiographic signs of failure}

The radiographic examination remains one of the main tools for recognition of failed implants in clinical practice. The most important factors for making an appropriate radiographic assessment of the implant conditions are the quality of the radiographs together with the examiner experience (16). Standardized periapical radiographs should be taken at regular follow-up intervals to detect peri-implant radiolucency and/or progressive marginal bone loss (20). At this point, the picture of peri-implant radiolucency suggests the absence of direct bone-implant contact and possibly a loss of stability, whereas in the case of increased marginal bone loss, the implant can be stable.

\section{Conclusion}

Despite high success rate with endosseous titanium implants, failures unavoidably occur. At an early stage, lack of primary stability, surgical trauma, peri-operative contamination and occlusal overload seem to be the most important causes of implant failure. 


\section{References}

1. Schwartz-Arad D, Laviv A, Levin L. Failure causes, timing, and cluster behavior: an 8-year study of dental implants. Implant Dent. 2008;17:200-7.

2. Albrektsson T, Zarb G, Worthington P, Eriksson AR. The longterm efficacy of currently used dental implants: a review and proposed criteria of success. Int J Oral Maxillofac Implants. 1986;1:1125.

3. Mombelli A, Lang NP. Clinical parameters for the evaluation of dental implants. Periodontol 2000. 1994;4:81-6.

4. Esposito M, Hirsch JM, Lekholm U, Thomsen P. Biological factors contributing to failures of osseointegrated oral implants. (I). Success criteria and epidemiology. Eur J Oral Sci. 1998;106:527-51.

5. Isidor F. Mobility assessment with the Periotest system in relation to histologic findings of oral implants. Int J Oral Maxillofac Implants. 1998;13:377-83.

6. Esposito M, Hirsch J, Lekholm U, Thomsen P. Differential diagnosis and treatment strategies for biologic complications and failing oral implants: a review of the literature. Int J Oral Maxillofac Implants. 1999;14:473-90.

7. Rosenberg ES, Torosian JP, Slots J. Microbial differences in 2 clinically distinct types of failures of osseointegrated implants. Clin Oral Implants Res. 1991;2:135-44.

8. Sánchez-Gárces MA, Gay-Escoda C. Periimplantitis. Med Oral Patol Oral Cir Bucal. 2004;9 Suppl:69-74; 63-9.

9. Zarb GA, Schmitt A. The longitudinal clinical effectiveness of osseointegrated dental implants: the Toronto study. Part III: Problems and complications encountered. J Prosthet Dent. 1990;64:185-94.

10. Ibbott CG, Kovach RJ, Carlson-Mann LD. Acute periodontal abscess associated with an immediate implant site in the maintenance phase: a case report. Int J Oral Maxillofac Implants. 1993;8:699702.

11. Esposito M, Hirsch JM, Lekholm U, Thomsen P. Biological factors contributing to failures of osseointegrated oral implants. (II). Etiopathogenesis. Eur J Oral Sci. 1998;106:721-64.

12. Mombelli A, Van Oosten MA, Schurch E Jr, Land NP. The microbiota associated with successful or failing osseointegrated titanium implants. Oral Microbiol Immunol. 1987;2:145-51.

13. O’Mahony A, Spencer P. Osseointegrated implant failures. J Ir Dent Assoc. 1999;45:44-51.

14. Worthington P, Bolender CL, Taylor TD. The Swedish system of osseointegrated implants: problems and complications encountered during a 4-year trial period. Int J Oral Maxillofac Implants. 1987;2:77-84.

15. Rams TE, Roberts TW, Tatum H Jr, Keyes PH. The subgingival microbial flora associated with human dental implants. J Prosthet Dent. 1984;51:529-34.

16. Gröndahl K, Lekholm U. The predictive value of radiographic diagnosis of implant instability. Int J Oral Maxillofac Implants. 1997;12:59-64.

17. Shulman LB, Rogoff GS, Savitt ED, Kent RL Jr. Evaluation in reconstructive implantology. Dent Clin North Am. 1986;30:327-49.

18. Sullivan DY, Sherwood RL, Collins TA, Krogh PH. The reverse-torque test: a clinical report. Int J Oral Maxillofac Implants. 1996;11:179-85.

19. Tricio J, Laohapand P, Van Steenberghe D, Quirynen M, Naert I. Mechanical state assessment of the implant-bone continuum: a better understanding of the Periotest method. Int J Oral Maxillofac Implants. 1995;10:43-9.

20. Brägger U. Radiographic parameters for the evaluation of periimplant tissues. Periodontol 2000. 1994;4:87-97. 